\title{
RETRACTED ARTICLE: An insightful 20-year recollection since the birth of pseudo amino acid components
}

\author{
Kuo-Chen $\mathrm{Chou}^{1}$ (D)
}

Received: 27 November 2019 / Accepted: 7 February 2020 / Published online: 18 February 2020

(c) Springer-Verlag GmbH Austria, part of Springer Nature 2020

The editors have retracted this article [1] because it is a duplicate publication of Chou 2019 [2], and there is significant overlap with previously published work [3] [4]. Further, there are a high number of citations to the author's previous work which have been deemed by post-publication peer review to be unrelated to the article. Kuo-Chen Chou disagrees with this retraction.

\section{References}

1. Chou, K. C. (2020). An insightful 20-year recollection since the birth of pseudo amino acid components. Amino Acids, 1-13

2. Chou KC. (2019) An Insightful 20-Year Recollection Since the Birth of Pseudo Amino Acid Components. J Math Stat Comput. 1(2):5-16

3. Chou, K. C. (2019). An insightful 10-year recollection since the emergence of the 5-steps rule. Current pharmaceutical design

4. Chou, K. C. (2011). Some remarks on protein attribute prediction and pseudo amino acid composition. Journal of theoretical biology, 273(1), 236-247

Electronic supplementary material The online version of this article (https://doi.org/10.1007/s00726-020-02828-1) contains supplementary material, which is available to authorized users.

Kuo-Chen Chou

kcchou@gordonlifescience.org; kcchou38@gmail.com

1 Gordon Life Science Institute, Boston, MA 02478, USA 